\title{
Ranking Economics Deparments Worldwide on the Basis of PHD Placement
}

R. Amir and M. Knauff

Discussion Paper 2005-41

Département des Sciences Économiques

de l'Université catholique de Louvain 


\title{
CORE DISCUSSION PAPER $2005 / 51$
}

\section{RANKING ECONOMICS DEPARTMENTS WORLDWIDE ON THE BASIS OF PHD PLACEMENT}

\author{
Rabah AMIR ${ }^{1}$, Malgorzata KNAUFF ${ }^{2}$
}

July 2005

\begin{abstract}
An objective ranking of economics departments worldwide in terms of graduate education is derived. The central idea is that the value of a department is the sum of the values of its $\mathrm{PhD}$ graduates, as reflected in the values of their current employing departments. The scores are thus derived as solutions to a linear system of simultaneous equations in the values. The sample includes the top fifty-four departments, the composition of which is determined endogenously using a criterion requiring a minimum of four placements in the departments comprising the sample. Two other related rankings are proposed, which place more emphasis on more recent faculty recruitments. The results point to a very high concentration in the economics $\mathrm{PhD}$ education market worldwide, confirming the dominance of the top U.S. departments, in particular of Harvard and M.I.T. Nevertheless, a modest de-concentration trend is under way. The rankings are in close agreement with the 1994 National Research Council survey ranking based on the perceived quality of $\mathrm{PhD}$ programs.
\end{abstract}

Keywords: economics $\mathrm{PhD}$ education, scientific evaluation methods, economics department ranking.

JEL classification: A14, L11, R32.

1Corresponding author: Department of Economics, University of Arizona, Tucson, AZ 85721, USA.

2 CORE, Universite de Louvain, 34 Voie du Roman Pays, 1348 Louvain la Neuve, Belgium, and Warsaw School of Economics, Poland.

This paper has benefited from the comments and suggestions of Dan Ackerberg, Claude d'Aspremont, Jacques Dreze, Glenn Ellison, Price Fishback, Jean Hindriks, Kei Hirano, Cuong Levan, Laurent Linnemer, Jean-Francois Mertens, Mark Stegeman, Jacques Thisse, Mark Walker, and John Wooders.

This text presents research results of the Belgian Program on Interuniversity Poles of Attraction initiated by the Belgian State, Prime Minister's Office, Science Policy Programming. The scientific responsibility is assumed by the authors. 


\section{Introduction}

A remarkable development in economic research is the emergence in recent years of a separate literature dealing exclusively with the evaluation of scientific performance at various levels. A typical study might yield as final output a ranking of such diverse items as scientific journals, separate journal articles, academic departments and/or individual economists. The multi-faceted need for some of these rankings is increasingly viewed as critical for the proper functioning of the academic sector. In particular, a proper and updated ranking of scientific journals provides a fundamental tool for university administrators to assess faculty research quality for promotion purposes, for junior faculty members to guide their submission process and to better plan their tenure period activities, and for academic departments to be evaluated in terms of their aggregate research output in a comparative perspective. 3 Similar trends have been observed in several other academic disciplines. 4

While most rankings in the past tended to be based on subjective methods such as opinion surveys of a relevant segment of the academic community5, a relatively recent trend comprises studies based on objective and mathematically well-founded methods. In the field of economics, this trend was pioneered by the journal ranking method devised by Liebowitz and Palmer (1984) and updated by Laband and Piette (1994). In the last few years, this trend has truly blossomed, giving rise to a myriad of studies providing rankings of journals and/or departments according to various standards: See Lubrano et. al. (2003), Combes and Linnemer (2003), Coupe (2003) and Kalaitzidakis et al. (2003) among others.

On the purely methodological or theoretical side, Ellison (2002a-b) proposes a game-theoretical model to explain the emergence of certain recently observed trends in the economics journal publication process. Palacios-Huerta and Volij (2004) develop an axiomatization of a journal ranking approach that modifies the Liebowitz-Palmer method by imposing an equal number of citations on all published articles, and illustrate its application on a sample of leading journals (see Amir, 2002 for an alternative perspective).

The aim of the present paper is to propose a ranking of economics departments worldwide based not on a measure of their research productivity but on the worth of their $\mathrm{PhD}$ program, as reflected in their ability to place their PhD graduates at top-level economics departments. The methodology adopted is a simple adaptation of the framework of Liebowitz and Palmer (1984) consisting of replacing journal citations by departmental hires, and thus gives rise to a purely objective ranking in terms of long-run academic placement.

The method may be concisely described as follows. Suppose that a sample of $n$ academic departments is given, along with a list of all faculty members employed by each department together with their $\mathrm{PhD}$ affiliations. The idea is to derive an endogenous relative valuation of each department on the basis of the above information alone. This is accomplished by specifying a system of $n$ equations wherein the value of department $i$ is a weighted average of the values of all other departments, with the $j$-th weight being the number of placements department $i$ has made in department $j$. Thus the value of each department's placement is given by the score of

\footnotetext{
${ }^{3}$ For about the last 20 years, universities in the U.K. periodically undergo government-mandated evaluations of individual academic departments in terms of aggregate research output, upon which a substantial portion of their research funding is contingent. Likewise, these departments are also evaluated on the basis of the quality of their teaching up to the M.A. level. Similar practices, consisting of tying funding to performance in some direct manner, are currently under consideration in several countries in the European Union.

${ }_{5}^{4}$ For instance Pinski and Narin (1976) deal with physics.

${ }^{5}$ A well-known example of the subjective approach is a ranking of $\mathrm{PhD}$ programs in economics in the U.S., conducted every ten years by the National Research Council as a survey of chairmen of economics departments
} 
the employing department, which is itself simultaneously determined in the underlying fixed-point relationship. The final score of a department is then simply the sum of all the values of its individual placements.

An alternative formulation, corresponding to the direct analog of the procedure of Liebowitz and Palmer (1984), is recursive. The first step simply counts the number of placements each department has in all the other departments in the sample. ${ }^{6}$ Dividing each of these numbers by the total number of faculty members in the sample gives a vector of $n$ weights. The second step uses the weight of each department thus obtained as a measure of the quality of the department and computes the step two value of each department as a qualityweighted sum of all its placements. This generates an updated vector of weights, and the process is repeated ad infinitum. Under very general conditions, the process converges fairly rapidly and the final outcome or solution is as described in the previous paragraph.

The simple principles underlying this procedure are quite general and have a broad scope of applicability encompassing any situation consisting of a system of $n$ elements characterized by a complete interaction structure, i.e. along a complete graph. Several applications of this procedure have been recorded in a variety of settings. Google uses a related algorithm to assign relative scores to web pages (see Page, et al., 1998). Using patent citation data, the value of industrial patents can be assessed via a similar "impact-adjusted" procedure (Hall, Jaffe and Trajtenberg, 2005). Not surprisingly, in all contexts considered, this methodology yields impact-adjusted scores that conform much more closely to expert opinion than a simple citation count, the latter being simply the first step in the above recursive algorithm. Indeed, by not weighting citations by the value of their source, one would typically arrive at outcomes that are easily seen not to be convincing, such as The Economist being the best economics journal. ${ }^{?}$

Within their respective contexts, faculty hires probably constitute a more reliable indicator of influence than journal citations. Indeed, the latter should ideally be distinguished in terms of their primary or secondary nature vis-à-vis the contents of the citing article, while the latter tend to be of more uniform value for the recruiting department on a priori grounds.

With most details about the data and some practical aspects of the procedure to be provided in the next section, we briefly describe the main characteristics here. The data used in the present study was collected in February-March 2004 directly from the web sites of the relevant economics departments. The actual size of the sample was determined in an endogenous manner by invoking a selection criterion that required a minimum of four $\mathrm{PhD}$ placements within the sample, at least two of which in departments outside the country of $\mathrm{PhD}$ graduation of the faculty members. The resulting final list of placements thus consists of faculty members that held a tenured or tenure-track position at any rank at one of the departments in the sample as of early 2004, irrespective of age. ${ }^{8}$ Appropriate measures were taken to harmonize inclusion requirements, and account for some idiosyncratic practices across the different national academic systems involved in the final sample, which were

in the U.S. Another such ranking is the more popularized survey conducted by the magazine U.S. News and World Report on a yearly basis.

${ }^{6}$ This total number of placements may itself be viewed as a crude measure of the value of a $\mathrm{PhD}$ program. We will indeed use this ranking as one of our comparative benchmarks below. Some journal rankings are indeed based solely on the total number of citations, and Liebowitz and Palmer also use this measure as a benchmark.

${ }^{7}$ In the case of patents, Hall, Jaffe and Trajtenberg (2005) report a wide array of studies pointing to the conclusion that citation-weighted patents constitute a much better measure than simple citation counts in a wide variety of settings, including as good proxies for the value of the firm.

${ }^{8}$ Observe that the use of the term placement in this context differs from its customary use in academic life. Indeed the latter usually refers to a $\mathrm{PhD}$ placement as being the first affiliation a fresh $\mathrm{PhD}$ graduate obtains upon completion of a $\mathrm{PhD}$. 
not compatible with the spirit and the objective of the present rankings. The benchmarks for all relevant comparisons were adapted from the U.S. academic system.

In addition to the primary ranking based directly on the Liebowitz-Palmer method, two other separate but related rankings are derived, both based on the same data set and part or all of the original sample of departments and following some modified version of the Liebowitz-Palmer procedure. These modifications are motivated by the desire to discount the importance of the past in an effort to derive conclusions that have more bearing on the present situation of the leading PhD programs in economics. One aspect of this consideration is to provide a ranking that does not entail clear biases against economics departments that were recently created or have undergone some major transformation. After all, one of the primary aims of the present exercise is to provide an up-to-date objective source of guidance in the choice of $\mathrm{PhD}$ programs for potential candidates, as an alternative to the established overall reputation of the institution. The details are described in the text.

Our main findings may be summarized as follows. $\mathrm{PhD}$ education in economics emerges as a highly concentrated activity, with the score distribution being very skewed to the top in all three rankings. Another reflection of the high concentration is that the total number of countries appearing in the rankings is surprisingly small: U.S., U.K., Canada, France, Spain, Belgium, Denmark and Australia. ${ }^{9}$ The well-known overall superiority of U.S. economics departments in terms of the general quality of their $\mathrm{PhD}$ graduates is unambiguously confirmed by these rankings. The overall level of concentration and the traditional dominance by the Harvard-M.I.T. duo have been declining over time, with substantial gains being achieved by other traditional top ten places such as Chicago, Stanford, Princeton, Yale and Northwestern. Non-U.S. universities have been making steady though modest progress in catching-up with U.S. departments. While some newly formed economics departments in Continental Europe have achieved scores comparable to those of existing leading departments there, U.S. departments that have undergone a major successful build-up in terms of faculty in the last fifteen years experienced an increase in their score that falls quite short of reflecting their current or recent strengths in terms of faculty quality. This is suggestive of the fact that entry at the upper end of the graduate school market is probably easier in the less competitive systems of Europe than in the more established U.S. market.

The rest of this paper is organized as follows. The next section describes the data used for the rankings, the methodology invoked and all appropriate adjustments carried out in order to make the country-specific data conform to the goals of the project. Section 3 contains the three different rankings themselves, and Section 4 provides a discussion of the results and appropriate conclusions based on all three rankings. Section 5 contains an extension.

\section{Data and Methodology}

\subsection{Data gathering}

For each economics department in the sample, we collected data on faculty members holding a full-time appointment at any academic rank (assistant, associate or full professor in the U.S. and analogous ranks at nonU.S. universities) during the academic year 2003/2004. For each individual, the information consisted of the date of $\mathrm{PhD}$ graduation, the granting university and the current affiliation, but not the history of employment.

\footnotetext{
${ }^{9}$ Though located in Italy, the European University Institute is a European-wide graduate school that functions according to international norms and programs.
} 
While consideration was limited to individuals holding appointments at economics departments only and not at business schools or other departments, we included all such individuals irrespective of their PhD discipline. Thus there is a small percentage of individuals holding PhDs from neighboring disciplines such as business administration and mathematical sciences. The justification for their inclusion is that these individuals typically had some connection to the economics department of their PhD-granting university through coursework and seminars and in most cases even worked with an economics faculty member as main or secondary adviser. They are thus part of the overall $\mathrm{PhD}$ output of the economics department of their home institutions. Conversely, many but unfortunately not all economics PhDs employed by business schools, public policy or social science departments also hold some type of appointment at the economics department of the same university, and have thus been counted as part of the list of that department. ${ }^{10}$

All this information was collected in February-March 2004 directly from the websites of the economics departments in the sample whenever the information was available and up to date. In some cases, we solicited parts of the requisite information or particular confirmations directly from the relevant departments or from national academic databases. (Some departments, particularly outside the U.S., still do not have parts of this information on their web sites at all. In some cases, the information was simply out of date.)

\subsection{Sample selection}

The single most important decision concerning this paper was to determine the criteria according to which the sample of economics departments would be delineated. Our final choice was guided by the following considerations. The sample should be large enough to ensure that the study would not amount to an update of where exactly the usual top ten departments stand today, and that it would not exclude some lesser-known places that have been undergoing serious improvements over the last two decades. The sample should also be broad enough to include a selection of economics departments outside of the U.S. to allow for international comparisons, and in particular to provide some objective information on the relative standing of some emerging departments outside of the U.S. On the other hand, the criteria must be demanding enough to include only departments that are making a recognized contribution to $\mathrm{PhD}$ education on a worldwide competitive basis, and to keep the data gathering and processing steps at a manageable level.

In the end, the criterion adopted is as follows.

Inclusion Criterion: To be included in the sample, a department must have placed at least four of its PhD graduates as current faculty members, as of March 2004, in economics departments included in the sample, with the further requirement that at least two of these PhD graduates are currently faculty members in a department located in a country other than that of their PhD-granting institution. ${ }^{I I}$

Invoking this criterion gave rise to an endogenous sample of fifty-four economics departments worldwide, which is just about the target size we had in mind as being appropriate and manageable for such a study. Naturally, there is no systematic way of uncovering these fifty-four departments, so our approach

\footnotetext{
${ }^{10}$ While including economics PhDs without such appointments seems reasonable on many grounds, it would have posed serious methodological difficulties in that it would have required an endogenous evaluation of the business schools as "economics departments" in view of the methodology invoked here, as will become clear below. Furthermore, this separate consideration of economics departments and business schools is in line with most other rankings of economics departments using different approaches.
} 
involved multiple steps of trial and error with the starting point being the top thirty U.S. departments as ranked according to research output by Dusansky and Vernon (1998). Observe that the criterion at hand is theoretically consistent with the emergence of multiple samples of departments, some of which are possibly disjoint. However, our trial and error steps indicated that this potentially troublesome issue was essentially unfounded for our purposes. ${ }^{12}$

While most of the reactions we received from colleagues about this criterion tended to argue that four was too low a threshold for inclusion in the sample, we felt it was desirable to err on the side of inclusion to include a significant number of international universities to allow for meaningful and representative comparisons. ${ }^{13}$ We point out though that this threshold of four was only binding for two departments, thresholds of five and six would each be binding for a further six departments, and a threshold of seven for a further two departments. Finally, twenty-one departments, i.e. roughly $40 \%$ of our sample, have placed at least twenty-two of their PhD graduates in the sample.

The additional requirement of placing at least two $\mathrm{PhD}$ graduates abroad, as opposed to simply in departments outside the graduating department, ${ }^{14}$ is justified on two separate grounds. First, it seems like a reasonable criterion to justify a contribution to $\mathrm{PhD}$ education at a worldwide competitive level, in view of the fact that economics is probably the most internationally integrated of all disciplines. Second, this requirement emerged as critical to rule out the presence of some departments that have succeeded in placing four or more $\mathrm{PhD}$ graduates in economics departments within the same country or even city (including their own department) as part of a hiring process motivated primarily by concerns outside of the competitive realm in the economics discipline. These considerations ended up being relevant in quite a few countries, including in particular Spain and France. ${ }^{15}$ In the converse direction, the additional requirement of two foreign placements did not disqualify any well-established department that would have otherwise qualified.

Another key dilemma we faced is to determine whether own hires (i.e. faculty members for whom the employing and the PhD-granting departments have constantly been the same, starting essentially at graduation ${ }^{16}$ )

\footnotetext{
${ }^{11}$ U.S. economics departments have not been subjected to this secondary requirement, the justification being that faculty hiring is well-known to be fully competitive amongst U.S. research universities. We will return to a detailed discussion of this secondary requirement below.

${ }^{12}$ There may possibly exist quite a few exceptions in the form of cases that are immaterial to the concerns of the present ranking, such as closed cliques of departments that hire each other's graduates within some country without regard to quality considerations.

${ }^{13}$ Another reason for this threshold is that it is actually convenient to use the same threshold for our second ranking where consideration is limited to younger faculty members. In this case, the same threshold is of course more demanding, as will be seen below.

${ }^{14}$ Naturally, without any additional requirement at all beyond placing four graduates in the sample, many more low-quality departments outside of the U.S. would have been included simply because they typically employ numbers of own hires that often exceed four people.

${ }^{15}$ For instance, without this requirement our sample would have included Universidad Complutense de Madrid and Universitat de Barcelona, which have placed business professors in Universidad Carlos III de Madrid and Universitat Pompeu Fabra respectively, with both of the latter being in the sample. In these particular cases, the difficulty at hand stems from the fact that the latter two economics departments include business administration. Similarly, without the foreign placement requirement, the dual nature of some U.K. universities such as Oxford and Cambridge, which are unusual combinations of first rate research institutions and teaching colleges, might have led to more U.K. universities entering the sample simply by placing teachers in those two places.

${ }^{16}$ A faculty member who was hired back by the PhD-granting department some years after $\mathrm{PhD}$ graduation is not considered an "own hire" for our purposes. There were several such cases at many institutions in our sample, including at some of the very best U.S. departments. A remarkable observation about these individuals in the case of U.S. departments is that they tended to have research records that were better than their average colleague, which is not surprising since the practice of own hiring of fresh PhDs has been eradicated quite some time ago in the U.S. So while "own hires" tend to be more often than not a signal of favoritism and weakness of the
} 
ought to count in the present ranking, both as part of the required minimum of four graduates placed in departments in the sample and as placements that contribute to the graduating department's final score. ${ }^{17}$ This issue is particularly troublesome in light of the fact that many non-U.S. departments continue to hire their own graduates on a somewhat regular basis for two generally opposite reasons. The first is that the local candidate may simply be the best person they could get in a particular year. The second, rather unfortunate, reason is that even some of the best European departments still have "old-fashioned" faculty members who, periodically if not systematically, attempt to restrict hiring to, or at least favor, their own graduates irrespective of quality considerations, and sometimes succeed in imposing their views on their more internationally oriented colleagues. In view of the sustained coexistence of these two conflicting ways of managing the hiring process at some of the departments in our sample, the appropriate course of action for the present study would be to select as best as we could, on the basis of faculty members' CVs, those who were probably hired according to international standards. To this end, we decided to include all individuals whose CV appeared consistent with a positive tenure decision within six to nine years of $\mathrm{PhD}$ graduation at a top sixty economics department in the U.S. ${ }^{18}$ This is obviously an approximate and somewhat subjective criterion. To actually make the determination for some borderline cases, we consulted to the extent possible with informed colleagues from the relevant departments or countries, or, in two decidedly difficult cases, simply used a "mixed strategy" by including one out of two such borderline faculty members.

\subsection{Methodology for the Primary Ranking}

Our primary ranking is based directly on an adaptation of The Liebowitz-Palmer method, which in the context of academic placements may be described as follows.

Let $q_{i j}$ be the number of PhD graduates from department $i$ employed by department $j$ as of March 2004, where $i$ and $j$ belong to our sample of departments, the selection of which was based on The Inclusion Criterion described in the previous section. Denote by $n$ the number of departments in the sample. Let $Q=\left[q_{i j}\right]_{n x n}$ denote the graduates' matrix and $\boldsymbol{q}=\left[q_{i}\right]_{n x l}$ be a vector whose i-th coordinate, $q_{i}=\sum_{j=1}^{n} q_{i j}$, is the total number of professors that graduated from department $i$. Moreover let $\boldsymbol{v}=\left[v_{i}\right]_{n \times l}$ be a non-zero vector of non-negative valuations, such that $\sum_{i=1}^{n} v_{i}=1$, called a transitory ranking. The Liebowitz and Palmer method can be described as follows. First we take the column vector $\boldsymbol{q}$ and divide each of its entries by the column sum. In this way we obtain the first ranking, which is treated as a vector of weights in the next iteration. We multiply the number of placements of the $i$-th department in, say, the $j$-th department, by the $j$-th department's weight. Again, we add these weighted numbers along each row and divide by the total, to get the next vector of weights, normalized to sum up to 1 . In symbols, the first iteration can be represented as

recipient's research record outside the U.S., these "hire backs" typically constitute rather a signal of high quality in U.S. departments.

${ }^{17}$ Indeed, according to the procedure at hand, every own hire, if counted, would end up contributing to the final score of the department some weighted amount of that same final score. It is thus important to devise a systematic way to discard bad self-hires for two separate reasons.

${ }^{18}$ While some readers may question the appropriateness of the frequent references made in this study to established practices in U.S. departments as implicit benchmarks for universities worldwide, we would defend this choice on account of the fact that it is probably the national system that has the most competitive and wellidentified (though multi-layered) standards and practices for the economics discipline. 


$$
v_{i, 1}=\frac{q_{i}}{\sum_{i=1}^{n} q_{i}}
$$

In general, the $h$-th iteration of this procedure can be represented as:

$$
v_{i, h}=\frac{\sum_{j=1}^{n} q_{i j} v_{j, h-1}}{\sum_{i=1}^{n} \sum_{j=1}^{n} q_{i j} v_{j, h-1}}
$$

In this way we obtain another ranking, the coordinates of which are used as weights in the next iteration of this procedure. Liebowitz and Palmer report that this process thus generated always converges after a small number of iterations. This is due to the fact that this procedure is equivalent to computing the positive eigenvector ${ }^{19}$ of the graduates' matrix $Q$.

\subsection{The Other Two Rankings}

While the above ranking provides a comprehensive view of the relative contribution of each economics department to international $\mathrm{PhD}$ education over the last forty years or so, it may a priori be quite a bit off the mark as a predictor of the quality of $\mathrm{PhD}$ education for the present time. Indeed, $\mathrm{PhD}$ education in economics is a relatively competitive activity, with highly mobile personnel, variability in the fortunes of the departments involved, and in particular with some entry of new players in the top league over the last fifteen years.

In order to provide an updated perspective that would reflect some of the recent developments, two other separate but related rankings are actually derived, all based on the same data and a subset of the original sample of departments and some suitably modified version of the Liebowitz-Palmer procedure. The first of these other rankings provides a $\lambda$-discounted version of the scores from the first ranking, wherein hires from the academic year 2003/2004 are taken at full value and hires $t$ years earlier are discounted by $\lambda$, with $\lambda=.98$, for $t$ ranging from 1 to 39,1954 being the year of earliest $\mathrm{PhD}$ graduation date for individuals included in the sample. The third and last ranking restricts consideration to graduates only from the academic year 1989-1990 to the academic year 2003-2004, with the original data being truncated accordingly, no discount factor used and all other characteristics of the ranking procedure kept the same. Clearly, maintaining the same Inclusion Criterion for placements over a shorter period obviously amounts to imposing a more stringent requirement on candidate departments. As a result, 17 departments from the original sample no longer qualify, reducing our sample from 54 to a subset consisting of 37 departments. ${ }^{20}$

In addition to offering a more updated picture, having the three rankings together will allow for various comparisons of interest, such as assessing the actual extent of some recent trends or changes in economics $\mathrm{PhD}$ education, e.g. the advent of some new departments in the top league. This will be discussed after a presentation of the data and the rankings.

\footnotetext{
${ }^{19}$ The existence and uniqueness of this eigenvector follows from the Perron - Frobenius theorem for positive irreducible matrices.

${ }^{20}$ A reasonable alternative would have been to lower the threshold number of placements to three, which would have given rise to both exit of some departments and entry of new ones. New entrants would have been the Stockholm School of Economics, The University of Aix-Marseille and The University of Namur, possibly among some others. Such a change would have necessitated an extensive review of the entire data set through inevitable cascade effects associated to each exogenous sample change, despite its limited impact and interest.
} 
All three rankings reflect a bias in favor of larger departments. While one might thus be tempted to normalize the final scores by faculty sizes in some way, we decided against such a step on account of the fact that faculty size and the concomitant diversity of scholarly expertise and availability for research mentoring are critical dimensions of $\mathrm{PhD}$ education.

\section{Results}

The three rankings under consideration are reported in this section. For the sake of brevity and to facilitate comparisons, the primary ranking and the $98 \%$-discounted ranking as well as the older rankings by the National Research Council and by Dusansky and Vernon (1998) are reported in Table 1 below.

To read Table 1, the meaning of the different columns is as follows, starting from the left. Column 1 is the primary ranking described in Section 2.3. Column 2 is the abbreviated name of the departments involved. Column 3 is their undiscounted score, normalized with 100 for the top department. Column 4 gives the total number of $\mathrm{PhD}$ graduates in the sample from each department. Column 5 is the average score per graduate (i.e. Column 3/Column 4). Column 6 is the normalized 98\%-discounted score. Column 7 is the 1994 National Research Council Ranking. Column 8 is the Dusansky-Vernon (1998) ranking. The mention "n.a.", short for "not applicable", means that the department in question is not present in the ranking (recall that the N.R.C. and Dusansky-Vernon rankings did not consider non-U.S. universities).

In Table 2, each column has the same meaning as the corresponding column in Table 1, the only change being that Table 2 only considers faculty members that graduated in 1990 or later. Of the original 54 departments, 17 failed the Inclusion Criterion and dropped out.

Table 3 provides different descriptive statistics relating to the rankings in both Table 1 and Table 2 . The equivalent of market share for a department is the ration of its score over the sum of all the scores of the 54 departments in the sample. HHI stands for the Herfindahl-Hirschman Index of industry concentration, defined as the sum of the squares of market shares. The "2 largest market share" is the ratio of the sum of the scores of the top two over the sum of all the 54 scores, etc... 
Table 1: Rankings based on the full sample, undiscounted normalized score (UNS) and 98\% discounted normalized score (98\% DNS) compared with rankings by the National Research Council (N.R.C.) and by Dusansky and Vernon (DV)

\begin{tabular}{|c|c|c|c|c|c|c|c|}
\hline \# & University & UNS & \# grads & UNS/\# grads & $98 \%$ DNS & N.R.C. & DV \\
\hline 1 & Harvard U & 100,00 & 164 & 56,64 & 100,00 & 5 & 2 \\
\hline 2 & MIT & 93,11 & 156 & 55,44 & 99,14 & 1 & 3 \\
\hline 3 & Stanford U & 38,29 & 110 & 32,33 & 43,47 & 4 & 9 \\
\hline 4 & Princeton U & 37,56 & 97 & 35,97 & 41,62 & 2 & 1 \\
\hline 5 & U Chicago & 35,69 & 106 & 31,27 & 38,76 & 3 & 17 \\
\hline 6 & UC - Berkeley & 30,01 & 98 & 28,44 & 31,12 & 7 & 12 \\
\hline 7 & Yale U & 29,21 & 92 & 29,49 & 29,86 & 9 & 7 \\
\hline 8 & Northwestern U & 12,68 & 89 & 13,24 & 16,61 & 8 & 5 \\
\hline 9 & Oxford U & 12,09 & 35 & 32,08 & 11,20 & n.a. & n.a. \\
\hline 10 & LSE & 10,53 & 46 & 21,26 & 12,66 & n.a. & n.a. \\
\hline 11 & U Minnesota & 9,51 & 57 & 15,50 & 10,26 & 6 & 18 \\
\hline 12 & U Pennsylvania & 9,04 & 39 & 21,54 & 9,58 & 11 & 3 \\
\hline 13 & U Michigan & 7,34 & 34 & 20,06 & 6,58 & 15 & 22 \\
\hline 14 & U Rochester & 5,84 & 40 & 13,56 & 5,75 & 10 & 12 \\
\hline 15 & Penn State & 5,38 & 5 & 100,00 & 7,58 & 39 & 28 \\
\hline 16 & Cambridge U & 5,21 & 24 & 20,18 & 4,62 & n.a. & n.a. \\
\hline 17 & Columbia U & 4,01 & 23 & 16,19 & 4,90 & 17 & 22 \\
\hline 18 & UC - Los Angeles & 3,91 & 22 & 16,51 & 5,13 & 16 & 21 \\
\hline 19 & U Wisconsin & 3,46 & 35 & 9,19 & 3,97 & 14 & 18 \\
\hline 20 & Johns Hopkins U & 3,40 & 15 & 21,08 & 2,93 & 26 & 15 \\
\hline 21 & U Maryland & 3,23 & 5 & 59,96 & 3,81 & 27 & 14 \\
\hline 22 & EHESS - Paris & 3,14 & 11 & 26,50 & 3,65 & n.a. & n.a. \\
\hline 23 & Cal Tech & 3,04 & 8 & 35,33 & 3,26 & 13 & 31 \\
\hline 24 & Duke U & 2,01 & 11 & 16,95 & 2,53 & 20 & 25 \\
\hline 25 & Carnegie Mellon U & 1,90 & 14 & 12,63 & 1,63 & n.a. & 37 \\
\hline 26 & U Paris I & 1,75 & 25 & 6,49 & 2,12 & n.a. & n.a. \\
\hline 27 & Brown U & 1,58 & 9 & 16,32 & 1,76 & 18 & 27 \\
\hline 28 & UC - San Diego & 1,58 & 18 & 8,13 & 1,89 & 12 & 9 \\
\hline 29 & Cornell U & 1,48 & 22 & 6,23 & 1,57 & 19 & 42 \\
\hline 30 & U College London & 1,35 & 6 & 20,86 & 1,96 & n.a. & n.a. \\
\hline 31 & U Toulouse & 1,34 & 16 & 7,77 & 2,10 & n.a. & n.a. \\
\hline 32 & Boston U & 1,23 & 11 & 10,35 & 1,73 & 32 & 7 \\
\hline
\end{tabular}




\begin{tabular}{|l|l|c|c|c|c|c|c|}
\hline 33 & U Virginia & 1,14 & 5 & 21,24 & 1,42 & 21 & 20 \\
\hline 34 & U Illinois/Urbana & 1,13 & 8 & 13,08 & 1,22 & 28 & 39 \\
\hline 35 & U Aarhus & 1,09 & 12 & 8,41 & 1,52 & n.a. & n.a. \\
\hline 36 & Purdue U & 1,03 & 10 & 9,55 & 0,75 & 36 & n.a. \\
\hline 37 & New York U & 1,00 & 10 & 9,28 & 1,54 & 22 & 6 \\
\hline 38 & U Pittsburgh & 0,64 & 6 & 9,97 & 0,87 & 33 & 15 \\
\hline 39 & Pompeu Fabra U & 0,58 & 6 & 8,91 & 0,94 & n.a. & n.a. \\
\hline 40 & U Western Ontario & 0,48 & 9 & 4,99 & 0,64 & n.a. & n.a. \\
\hline 41 & U Louvain/CORE & 0,47 & 26 & 1,68 & 0,64 & n.a. & n.a. \\
\hline 42 & U British Columbia & 0,40 & 8 & 4,61 & 0,37 & n.a. & n.a. \\
\hline 43 & ANU & 0,39 & 11 & 3,28 & 0,38 & n.a. & n.a. \\
\hline 44 & U Washington & 0,31 & 6 & 4,73 & 0,24 & 23 & 36 \\
\hline 45 & Queen's U & 0,30 & 16 & 1,73 & 0,34 & n.a. & n.a. \\
\hline 46 & U Paris 9 & 0,24 & 12 & 1,83 & 0,27 & n.a. & n.a. \\
\hline 47 & U Iowa & 0,23 & 6 & 3,51 & 0,35 & 29 & 30 \\
\hline 48 & European U Institute & 0,13 & 12 & 0,97 & 0,24 & n.a. & n.a. \\
\hline 49 & Rice U & 0,12 & 6 & 1,80 & 0,08 & 53 & 48 \\
\hline 50 & SUNY - Stony Brook & 0,10 & 4 & 2,33 & 0,18 & 40 & n.a. \\
\hline 51 & U Toronto & 0,08 & 7 & 1,09 & 0,08 & n.a. & n.a. \\
\hline 52 & U Carlos III - Madrid & 0,06 & 4 & 1,50 & 0,10 & n.a. & n.a. \\
\hline 53 & U Autonoma - Barcelona & 0,06 & 12 & 0,47 & 0,11 & n.a. & n.a. \\
\hline 54 & UC - Davis & 0,02 & 7 & 0,28 & 0,05 & 50 & 28 \\
\hline
\end{tabular}


Table 2: Truncated-sample normalized score (TSNS), based on data from PhD graduates from 1990 onwards.

\begin{tabular}{|c|c|c|c|c|}
\hline \# & University & TSNS & \# grads & TSNS /\# grads \\
\hline 1 & MIT & 100,00 & 39 & 76,07 \\
\hline 2 & Harvard U & 87,96 & 43 & 60,69 \\
\hline 3 & U Chicago & 65,09 & 32 & 60,35 \\
\hline 4 & Stanford U & 59,34 & 36 & 48,91 \\
\hline 5 & Princeton U & 43,84 & 28 & 46,45 \\
\hline 6 & Yale U & 30,13 & 23 & 38,87 \\
\hline 7 & Northwestern U & 29,83 & 43 & 20,58 \\
\hline 8 & UC - Berkeley & 28,95 & 31 & 27,71 \\
\hline 9 & LSE & 21,33 & 23 & 27,51 \\
\hline 10 & Penn State U & 13,48 & 4 & 100,00 \\
\hline 11 & U Minnesota & 13,41 & 19 & 20,94 \\
\hline 12 & U Pennsylvania & 9,79 & 17 & 17,08 \\
\hline 13 & EHESS - Paris & 8,89 & 10 & 26,37 \\
\hline 14 & UC - Los Angeles & 8,65 & 8 & 32,10 \\
\hline 15 & U Toulouse & 8,02 & 13 & 18,29 \\
\hline 16 & U Michigan & 6,26 & 6 & 30,96 \\
\hline 17 & U College London & 5,81 & 5 & 34,46 \\
\hline 18 & Boston U & 4,94 & 10 & 14,66 \\
\hline 19 & U Paris I & 4,86 & 12 & 12,02 \\
\hline 20 & U Rochester & 4,81 & 12 & 11,89 \\
\hline 21 & New York U & 4,51 & 7 & 19,13 \\
\hline 22 & Oxford U & 3,97 & 7 & 16,81 \\
\hline 23 & U Wisconsin & 3,29 & 9 & 10,86 \\
\hline 24 & U Aarhus & 3,11 & 9 & 10,25 \\
\hline 25 & Pompeu Fabra U & 3,02 & 4 & 22,41 \\
\hline 26 & Cornell U & 2,03 & 6 & 10,04 \\
\hline 27 & U Pittsburgh & 1,87 & 4 & 13,85 \\
\hline 28 & European U Institute & 1,82 & 12 & 4,50 \\
\hline 29 & U Louvain/CORE & 1,59 & 12 & 3,93 \\
\hline 30 & UC - San Diego & 0,99 & 7 & 4,19 \\
\hline 31 & Cambridge U & 0,85 & 5 & 5,02 \\
\hline 32 & U Carlos III - Madrid & 0,61 & 4 & 4,52 \\
\hline 33 & U Autonoma - Barcelona & 0,60 & 8 & 2,21 \\
\hline 34 & Carnegie Mellon U & 0,41 & 4 & 3,02 \\
\hline 35 & UC - Davis & 0,39 & 7 & 1,67 \\
\hline 36 & Queen's U & 0,33 & 5 & 1,98 \\
\hline 37 & U British Columbia & 0,05 & 4 & 0,39 \\
\hline
\end{tabular}


Table 3A: Descriptive statistics for Table 1

\begin{tabular}{|c|c|c|}
\hline & UNS & UNS/\# grads \\
\hline HHI & 1059.42 & 389.28 \\
\hline 2-largest market share & 39.42 & 17.15 \\
\hline 4-largest market share & 54.91 & 29.17 \\
\hline 7-largest market share & 74.28 & 40.28 \\
\hline Correlation (UNS, \# grads) & \multicolumn{2}{|c|}{0.92514} \\
\hline Correlation (UNS /\# grads, \# grads) & \multicolumn{2}{|c|}{-0.45713} \\
\hline Correlation (UNS, UNS /\# grads) & \multicolumn{2}{|c|}{-0.55186} \\
\hline
\end{tabular}

Table 3B: Descriptive statistics for Table 2

\begin{tabular}{|c|c|c|}
\hline & TSNS & TSNS /\# grads \\
\hline HHI & 918.36 & 517.62 \\
\hline 2-largest market share & 32.14 & 20.46 \\
\hline 4-largest market share & 53.42 & 34.52 \\
\hline 7-largest market share & 71.17 & 50.12 \\
\hline Correlation (TSNS, \# grads) & \multicolumn{2}{|c|}{0.874905} \\
\hline Correlation (TSNS /\# grads, \# grads) & \multicolumn{2}{|c|}{0.522761} \\
\hline Correlation (TSNS, TSNS /\# grads) & \multicolumn{2}{|c|}{0.733562} \\
\hline
\end{tabular}




\section{Discussion of the results}

This section provides a general analysis of the three rankings and draws conclusions of potential interest to educators, graduate students and policy makers. We begin with general observations that can be seen from a cursory inspection of the three rankings. Each ranking provides a cardinal score for each economics department in the sample and thus allows for some precise comparisons of a cardinal nature. $\mathrm{PhD}$ education in economics emerges as a highly concentrated activity, with the top few departments scoring substantially higher than the other departments in all three rankings. Another reflection of the high concentration is that the number of countries appearing in the rankings is surprisingly small: US, UK, Canada, France, Spain, Australia, Belgium and Denmark. The latter three countries are each represented only by one institution in the sample. The wellknown overall superiority of U.S. economics departments in terms of the general quality of $\mathrm{PhD}$ graduates is strongly reflected in these rankings. ${ }^{21}$ In view of the very low relative scores of the departments at the bottom of the two rankings, the fact that the Inclusion Criterion did indeed err on the side of inclusion is rather clearly confirmed by our analysis. As a consequence, including more departments by imposing less stringent overall placement requirements would have resulted in a negligible gain in precision for the present ranking.

We now turn to some elaboration on these conclusions and to a review of the less obvious implications of the rankings, keeping a comparative perspective across them.

The overall "industry" concentration has decreased over time. Table 3 gives various standard measures of industry concentration used in industrial organization. All of these measures point to a modest increase in the level of competition from the first ranking to the second. In particular, the overwhelming dominance of Harvard and MIT in the first ranking has definitely shrunk in the second, although it still persists to a remarkable extent. In the reverse direction, in the top league, Chicago, Stanford and Northwestern recorded notable gains. Another noteworthy observation is the extremely steep rate of decline of the scores as one moves down the rankings, confirming that, with few exceptions, only top departments manage to place $\mathrm{PhD}$ graduates in top departments on a regular basis.

These findings are consistent with some different but related studies ranking individual economists on the basis of research output alone. In particular, Coupe (2003) develops a ranking of the top 100 most researchproductive individual economists in the world and reports an extremely high level of concentration, with $25 \%$ of these exceptional scholars having obtained their $\mathrm{PhD}$ from MIT, 14\% from Harvard, 9\% from Princeton, and 7\% from each of Chicago and UC-Berkeley. While rankings of economics departments on the basis of faculty research productivity also produce outcomes that are lop-sided at the top, scores tend to fall at a much lower rate as one moves down the ranking. This may be seen for instance in the recent ranking in [Combes and Linnemer (2003), Appendix B]. Likewise, the latter study also illustrates the fact that the gap in scores between the top U.S. and non-U.S. departments is less dramatic in research rankings than it is in our PhD program ranking.

The present rankings reflect some modest tendency for the gap between US and non-US departments to be shrinking over time. The latter comprised 19 out of 54 departments (or 35\%) in the first ranking and 14 out of 37 (or 38\%) in the second ranking. Thus their market share increased from $8 \%$ to $10 \%$ of the total. While

\footnotetext{
${ }^{21}$ Indeed, virtually all internationally-oriented non-U.S. economics departments that are strongly committed to competitive hiring attend the North-American ASSA meetings and tend to concentrate their recruitment effort on those selected graduates of good U.S. departments that appear promising in terms of their potential to move to,
} 
these gains are rather minor, it is nevertheless noteworthy that many of the non-US departments have made most of their non-local placements (those excluding own hires) in the last 15 years. In other words, their number of placements is only slightly lower in the second than in the first ranking. The reason this observation does not have a significant impact on their overall score is simply that their placements are often limited to departments that appear at the lower end of the ranking.

It is well known that several departments have entered the global market for PhD education in the last fifteen years, at a level that earned them a place in the present rankings. Some of these are drastically improved departments (Boston University and New York University in the US and the University of Toulouse in France) while others are part of newly founded universities (Pompeu Fabra and Carlos III, both of which are located in Spain). The second ranking based on younger faculty members was partly motivated by the desire to assess the current standing of these departments without any bias in favor of older established departments. Although Boston University and New York University have had first-rate faculty members for many years now, their scores in the present rankings - including in the recent and discounted versions - are surprisingly low. On the other hand, the performance of Toulouse, Pompeu Fabra and Carlos III is already on a par with the best economics departments in Europe. ${ }^{22}$ This suggests that in the more established and more competitive US market, successful entry into the top-level league is harder than in Europe, confirming the perhaps unfortunate observation that the global reputation of a graduate program takes longer to establish outside the circle of academic economists and that a substantial lag exists between achieving a first-rate faculty and attracting toplevel graduate students and turning them into first-rate $\mathrm{PhD}$ economists. In the less competitive European market, a group of quality scholars, in many cases led by one visionary individual, may create or improve an existing department and bring it to leading international, though perhaps not elite, standards.

The first step of the recursive version of the ranking method, as described in the Introduction, simply describes the total number of placements each department has made in all the departments included in the sample. As such, it already incorporates some measure of quality of the $\mathrm{PhD}$ program since our sample comprises only the highest-scoring departments in terms of $\mathrm{PhD}$ placement. It is shown in Column 4 of Table 1. A somewhat surprising outcome is that the rankings of Column 4 and Column 3 are remarkably similar, as reflected in the correlation coefficient of UNS with \# grads in Table 3. While this stands in sharp contrast to the cases of journals and patents, this result simply reflects the fact that the best PhD programs are also those that produce the largest numbers of top-level $\mathrm{PhDs}$, which is quite natural in view of the characteristics of this market. Indeed, the best programs receive more quality graduate applications, can thus afford larger faculties and provide a richer program with a more diversified set of courses and a closer supervision of $\mathrm{PhD}$ research.

Column 5 in Table 1 may be viewed as the average value of the good placements of a department. Indeed, it would be erroneous to regard it as the average value of all the placements of a department simply because our study limited consideration to placements in the top 54 places. This observation underscores the presence of a bias in favor of the departments at the bottom of our ranking since more of the lower tail of their placements has been truncated by our procedure. It is nonetheless noteworthy that Penn State University emerges as the \#1 department according to this measure. Another remarkable observation is that the ranking of the last

and remain in, their country of location. The present rankings thus vindicate the well-founded nature of this broadly observed hiring strategy.

${ }^{22}$ It should be added that the Spanish universities have probably encountered less severe administrative difficulties than Toulouse on their innovative path to international excellence. 
column is not substantially different from that of the first column. In other words, a high overall score in total placements means a high average score as well.

The National Research Council (N.R.C.), a branch of the U.S. National Science Foundation establishes a ranking of graduate programs in the U.S. for several academic disciplines including economics on a regular basis. Their most recent ranking, conducted in 1994, is based on a multi-criterion assessment relying on survey data, and is available in an interactive manner on the Internet.23 Users may select amongst twenty different criteria and the weights on a scale of 1 to 5 that they ascribe to each of the selected criteria, and receive the corresponding ranking. Reported in column N.R.C. of Table 1 is the ranking based exclusively on the criterion of "Educational Effectiveness", which, of the N.R.C. criteria, in most closely related to PhD placement ability. This ranking is surprisingly close to ours (restricted to U.S. departments), with a few outliers that may be partly explained by contrasting the long run nature of our ranking with the fact that this NRC ranking refers specifically to the period 1984-1994.

By contrast, the comparison of our ranking with the research productivity rankings of the top fifty U.S. departments by Dusansky and Vernon (1998), reported in Column 8 of Table 1, reveals larger discrepancies. A key reason is that research output rankings are known to have pervasive variations across time periods, which in part reflects the high mobility of economics professors. Nevertheless, it is worthwhile to observe that this research ranking can be invoked to confirm that newly reformed economics departments such as Boston University, New-York University and U.C.-San-Diego have achieved a very high rank in terms of the quality of their faculty24. Yet, in our ranking, their standing is not nearly as high. Similar comments apply to the University of Texas at Austin, which did not even make it to the top fifty-four worldwide in our ranking.25 Again, this is further evidence of the reputation lag that accompanies a new and drastic department build-up. Another likely contributing factor is the fact that the overall name of a university plays a major determining role in the ability of its departments to attract highly qualified graduate students.

\section{An extension}

The rankings derived so far are all predicated on the central idea that the value of an economics department is the sum of all the values of its $\mathrm{PhD}$ graduates that are currently employed at one of the top fiftyfour economics department in the world, with the value of each $\mathrm{PhD}$ graduate being taken as the value of the employing department.

A dual version of the underlying logic would proceed on the postulate that the value of an economics department is the sum of all the values of its current faculty members, which are in turn the values of the economics departments of their respective $\mathrm{PhD}$ alma maters. After all, the recruitment of a faculty member is best viewed as a bilateral match in a competitive market, in which case both our original method and the aforementioned dual version might a priori be plausible ways of assigning values to economics departments.

Methodologically, this dual view is easily handled in analogous ways, using the same data in a similar way. A moment's reflection along the lines of the arguments of Section 2.3 will reveal that the procedure

\footnotetext{
${ }^{23}$ See http://www.phds.org/rankings/getWeights.php?d=28.

${ }^{24}$ The first two departments were ranked, on the basis of faculty research output in the Fall of 1995, sixth and seventh respectively by Dusansky and Vernon (1998).

${ }^{25}$ Interestingly, the aforementioned four departments are the top four departments in the N.R.C. ranking based on the criterion of "Change in Quality", i.e. on a measure the level of progress made in recent years. This ranking is not reported in the present paper, but may easily be seen on the web site given above.
} 
amounts to calculating the largest positive eigenvector of the transpose of the graduates' matrix Q. The details are left out for the sake of brevity.

The results corresponding to the dual view are reported in Table 4. Column 1 gives the ranking, Column 2 provides the abbreviated names of the universities, Column 3 contains the value of the department normalized so that 100 goes to the top department, in Column 4 there are the number of faculty members currently employed by the department, and Column 5 gives the subset of the faculty that received their $\mathrm{PhD}$ from a department in the sample. 
Table 4: "Dual" ranking of Section 5.

\begin{tabular}{|c|c|c|c|c|}
\hline$\#$ & Universities & UNS & Faculty size & Actual Faculty size \\
\hline 1 & U Michigan & 100,00 & 62 & 60 \\
\hline 2 & Harvard U & 97,66 & 56 & 55 \\
\hline 3 & UC - Berkeley & 94,10 & 60 & 58 \\
\hline 4 & Princeton U & 89,93 & 62 & 57 \\
\hline 5 & U Toronto & 73,03 & 57 & 51 \\
\hline 6 & Yale U & 68,83 & 45 & 44 \\
\hline 7 & Columbia U & 68,52 & 39 & 38 \\
\hline 8 & Stanford U & 66,48 & 43 & 43 \\
\hline 9 & UC - Los Angeles & 64,36 & 50 & 48 \\
\hline 10 & LSE & 61,71 & 51 & 42 \\
\hline 11 & MIT & 57,92 & 37 & 37 \\
\hline 12 & New York U & 56,29 & 41 & 40 \\
\hline 13 & U Maryland & 55,02 & 39 & 37 \\
\hline 14 & UC - San Diego & 54,69 & 36 & 35 \\
\hline 15 & U Illinois & 53,05 & 40 & 38 \\
\hline 16 & Northwestern U & 52,25 & 41 & 40 \\
\hline 17 & Pompeu Fabra U & 52,03 & 78 & 47 \\
\hline 18 & UC - Davis & 50,78 & 32 & 30 \\
\hline 19 & Carnegie Mellon U & 50,50 & 40 & 39 \\
\hline 20 & Cornell U & 48,10 & 36 & 35 \\
\hline 21 & Boston U & 45,56 & 34 & 30 \\
\hline 22 & Duke U & 45,24 & 37 & 34 \\
\hline 23 & U Wisconsin & 43,68 & 32 & 31 \\
\hline 24 & U British Columbia & 42,25 & 32 & 30 \\
\hline 25 & Brown U & 41,50 & 32 & 28 \\
\hline 26 & U Washington & 40,66 & 30 & 28 \\
\hline 27 & U Chicago & 38,05 & 32 & 32 \\
\hline 28 & Oxford U & 37,72 & 53 & 28 \\
\hline 29 & U Pennsylvania & 36,76 & 32 & 31 \\
\hline
\end{tabular}




\begin{tabular}{|c|c|c|c|c|}
\hline 30 & U Virginia & 33,16 & 29 & 26 \\
\hline 31 & U Carlos III - Madrid & 32,63 & 54 & 37 \\
\hline 32 & U Minnesota & 31,32 & 29 & 27 \\
\hline 33 & U Western Ontario & 30,68 & 32 & 28 \\
\hline 34 & Penn State & 29,15 & 27 & 25 \\
\hline 35 & Queen's U & 28,74 & 25 & 24 \\
\hline 36 & Cal Tech & 27,13 & 23 & 22 \\
\hline 37 & U Autonomia - Barcelona & 25,77 & 42 & 29 \\
\hline 38 & U Rochester & 24,72 & 23 & 22 \\
\hline 39 & U Iowa & 23,27 & 23 & 21 \\
\hline 40 & Rice U & 23,03 & 20 & 19 \\
\hline 41 & U College London & 22,96 & 35 & 24 \\
\hline 42 & Cambridge U & 22,21 & 39 & 19 \\
\hline 43 & Johns Hopkins U & 20,78 & 14 & 14 \\
\hline 44 & SUNY - Stony Brook & 20,35 & 16 & 15 \\
\hline 45 & Purdue U & 19,41 & 21 & 19 \\
\hline 46 & U Pittsburgh & 17,85 & 23 & 18 \\
\hline 47 & ANU & 17,20 & 65 & 16 \\
\hline 48 & U Toulouse I & 10,54 & 36 & 22 \\
\hline 49 & EHESS - Paris & 8,84 & 25 & 13 \\
\hline 50 & European U Institute & 8,11 & 12 & 10 \\
\hline 51 & U Louvain/CORE & 6,16 & 25 & 16 \\
\hline 52 & U Paris I & 3,23 & 45 & 16 \\
\hline 53 & U Paris 9 & 2,56 & 8 & 5 \\
\hline 54 & U Aarhus & 1,84 & 18 & 13 \\
\hline
\end{tabular}

A brief inspection of Table 4 reveals that this new ranking is unnatural in many respects, and that it violates most experts' beliefs about the relative merits of economics departments in terms of graduate education. A brief calculation indicates that the correlation coefficient between this ranking and the departments' sizes restricted to professors that graduated from universities in the sample (or Column 5 in Table 4) is extremely high: $95 \%$ ! In other words, this ranking essentially mirrors the faculty sizes of the departments involved.

What one learns from this exercise is the confirmation of the well-known fact that most good economics departments hire their faculty members mostly from the very top departments, so that only minor differences exist between the distributions of faculty members' alma maters across different departments in our sample. 
The reason this approach could not conceivably produce a plausible ranking is that it relies on a critical assumption that is well-known not to be even approximately valid, namely that all $\mathrm{PhD}$ graduates from the same department have the same value. While we report this dual ranking for the sake of completeness, it is not purported in the authors' minds to represent a reasonable alternative to the original rankings. 


\section{Appendix}

The appendix provides the list of full names of all fifty-four universities in the sample along with the corresponding abbreviation used, in the order corresponding to the primary ranking given in Table 1.

\begin{tabular}{|c|c|}
\hline Standard name of university & Abbreviation \\
\hline Harvard University & Harvard U \\
\hline Massachusetts Institute of Technology & MIT \\
\hline Stanford University & Stanford U \\
\hline Princeton University & Princeton U \\
\hline University of Chicago & U Chicago \\
\hline University of California at Berkeley & UC - Berkeley \\
\hline Yale University & Yale U \\
\hline Northwestern University & Northwestern U \\
\hline Oxford University & Oxford U \\
\hline London School of Economics & LSE \\
\hline University of Minnesota & U Minnesota \\
\hline University of Pennsylvania & U Pennsylvania \\
\hline University of Michigan & U Michigan \\
\hline University of Rochester & U Rochester \\
\hline Pennsylvania State University & Penn State \\
\hline Cambridge University & Cambridge U \\
\hline Columbia University & Columbia U \\
\hline University of California at Los Angeles & UC - Los Angeles \\
\hline University of Wisconsin & U Wisconsin \\
\hline Johns Hopkins University & Johns Hopkins U \\
\hline University of Maryland & U Maryland \\
\hline Ecole des Hautes Etudes Sciences Sociales & EHESS - Paris \\
\hline California Institute of Technology & Cal Tech \\
\hline Duke University & Duke U \\
\hline Carnegie Mellon University & Carnegie Mellon U \\
\hline University of Paris I & U Paris I \\
\hline Brown University & Brown U \\
\hline University of California at San Diego & UC - San Diego \\
\hline Cornell University & Cornell U \\
\hline University College London & U College London \\
\hline University of Toulouse & U Toulouse \\
\hline Boston University & Boston U \\
\hline University of Virginia & U Virginia \\
\hline
\end{tabular}




\begin{tabular}{|l|l|}
\hline University of Illinois, Urbana & U Illinois/Urbana \\
\hline University of Aarhus & U Aarhus \\
\hline Purdue University & Purdue U \\
\hline New York University & New York U \\
\hline University of Pittsburgh & U Pittsburgh \\
\hline Universitat Pompeu Fabra & Pompeu Fabra U \\
\hline University of Western Ontario & U Western Ontario \\
\hline Catholic University of Louvain & U Louvain/CORE \\
\hline University British Columbia & U British Columbia \\
\hline Australian National University & ANU \\
\hline University of Washington & U Washington \\
\hline Queen's University & Queen's U \\
\hline University of Paris 9 & U Paris 9 \\
\hline University of Iowa & U Iowa \\
\hline European University Institute & European U Institute \\
\hline Rice University & Rice U \\
\hline State University of New York at Stony Brook & SUNY - Stony Brook \\
\hline University of Toronto & U Toronto \\
\hline Carlos III University, Madrid & U Carlos III - Madrid \\
\hline Universitat Autònoma, Barcelona & U Autonoma - Barcelona \\
\hline University of California at Davis & UC - Davis \\
\hline & \\
\hline
\end{tabular}




\section{References}

Amir, R. (2002), Impact-Adjusted Citations as a Measure of Journal Quality, CORE Discussion Paper 2002/74, University of Louvain.

Combes, P-P. and L. Linnemer (2003), Where are the Economists Who Publish? Publication Concentration and Rankings in Europe Based on Cumulative Publications, Journal of the European Economic Association, 1, 1250-1308.

Coupe, T. (2003), Revealed Performances: Worldwide Rankings of Economists and Economics Departments, 1990-2000, Journal of the European Economic Association, 1, 1309-1345.

Ellison, G. (2002a), The Slowdown of the Economics Publishing Process, Journal of Political Economy, 105, 947-993.

Ellison, G. (2002b), Evolving Standards for Academic Publishing: A q-r Theory, Journal of Political Economy, 105, 994-1034.

Dusansky, R. and C. J. Vernon (1998), Rankings of U.S. Economics Departments, Journal of Economic Perspectives, vol. 12 (1), 157-170;

Hall, B., Adam Jaffe and Manuel Trajtenberg (2005), Market Value and Patent Citations, Rand Journal of Economics 36, 16-38.

Kalaitzidakis, P., T. Mamuneas and T. Stengos (2003), Ranking of Academic Journals and Institutions in Economics, Journal of the European Economic Association, 1, 1346-1366.

Laband, D.N. and M.J. Piette (1994), The Relative Impact of Economics Journals: 1970-1990, Journal of Economic Literature, XXXII, 640-666.

Liebowitz, S.J. and J.P Palmer (1984), Assessing the Relative Impact of Economics Journals, Journal of Economics Literature, vol. XXII, 77- 88.

Lubrano, M., Bauwens, L., Kirman A. and C. Protopopescu (2003), Ranking Economics Departments in Europe: A Statistical Approach, Journal of the European Economic Association, 1, 1367-1401.

Page, L.; Brin, S.; Motwani, R.; and T. Winograd (1998), The PageRank Citation Ranking: Bringing Order to the Web, Technical report, Stanford University.

Palacios-Huerta, I. and O. Volij (2004), The Measurement of Intellectual Influence, Econometrica, 72, 963-977. Pinski, G. and F. Narin (1976), Citation Influence for Journal Aggregates of Scientific Publications: Theory, with Applications to the Literature of Physics, Information Processing and Management, 12, 297-312. 
Département des Sciences Économiques de l'Université catholique de Louvain

Institut de Recherches Économiques et Sociales

Place Montesquieu, 3

1348 Louvain-la-Neuve, Belgique 